\title{
Electrodeposition of Nickel Particles and their Characterization
}

\author{
Gerardo T. Martínez, ${ }^{* 1}$ Genaro Zavala, ${ }^{2}$ and Marcelo Videa ${ }^{3}$
}

${ }^{1}$ Laboratorio de Microscopía. Centro de Investigación en Química Aplicada. Blvd. Enrique Reyna \# 140, Saltillo 25253, Coahuila, Mexico.gtadeo@ciqa.mx

2 Departamento de Física. Instituto Tecnológico y de Estudios Superiores de Monterrey, Campus Monterrey, Avenida Garza Sada 2501 Sur, Monterrey, N.L., 64849, México. (+52) 8183582000 ext 4631. genaro.zavala@itesm.mx

${ }^{3}$ Departamento de Química. Instituto Tecnológico y de Estudios Superiores de Monterrey, Campus Monterrey, Av. Garza Sada 2501 Sur, Monterrey, N.L., 64849, México. (+52) 8183582000 ext 4513. mvidea@itesm.mx

Received July 30, 2008; accepted February 17, 2009

\begin{abstract}
Electrodeposition of nickel particles on ITO substrates is achieved by current pulse reduction. A comparison between potential pulse and current pulse experiments presents differences in particle size and particle size distribution. The latter shows smaller particle size dispersion than what is found with potential pulses. Characterization of the particles carried out by Atomic Force Microscopy shows particles with average sizes between 100 to 300 nm. Magnetic characterization by Magnetic Force Microscopy and SQUID shows that particles of $\sim 300 \mathrm{~nm}$ were ferromagnetic with a coercive field of $200 \mathrm{Oe}$ and a saturation magnetization of $40 \times 10^{-6}$ emu at $300 \mathrm{~K}$
\end{abstract}

Key words: Electrodeposition, magnetic nanoparticles, Atomic Force Microscopy, Magnetic Force Microscopy.

\section{Introduction}

The development of methods that allow controlled growth of metallic particles has gained special interest due to novel applications in electrocatalysis, data storage, and the construction of devices at nanotechnology. These applications demand a controlled production of particles with specific dimensions and low size dispersion, through procedures that make it feasible to bring them into industrial application. Electrodeposition of metallic particles through a double potential pulse technique has been studied extensively [1]. The potentionstatic doublepulse procedure, characterized by the pulses $E_{1}$ and $E_{2}$ and their corresponding pulse durations $t_{1}$ and $t_{2}$, is an efficient way to control the particle size distributions of electrodeposits. It is based on the knowledge of the critical potential for the system, $E_{\text {crit, }}$ which is the minimal potential that has to be applied in order to allow the formation of nuclei. The first pulse, which should be more negative than $E_{\text {crit }}$, is used to initiate the formation of the nuclei and the second pulse, less negative than $E_{\text {crit }}$ but more negative than the reversible potential, is used to control the growth of the nuclei formed during the previous pulse [2]. To achieve particle growth, the overpotential of the second pulse must be low enough to inhibit generation of new nuclei. Under such circumstances, the original distribution of stable nuclei formed during the first pulse should be preserved [3]. The mechanism of nucleation and growth has also been studied and it is concluded that depending on the potential of the applied pulse, the nucleation can be either instantaneous or progressive [4-7].
Resumen. Se realizó la electrodeposición de partículas de níquel sobre substratos de ITO mediante la aplicación de pulsos de corriente. La comparación entre el método de pulsos de potencial y pulsos de corriente muestra diferencias en el tamaño de partícula y su distribución. El método de pulsos de corriente conduce a una menor dispersión en el tamaño de partícula que el observado con pulsos de potencial. La caracterización de las partículas se llevó a cabo por Microscopía de Fuerza Atómica mostrando partículas con un tamaños promedio entre 100 y $300 \mathrm{~nm}$. Mediante Microscopía de Fuerza Magnética y SQUID se determinó que partículas de $\sim 300 \mathrm{~nm}$ son ferromagnéticas, con un campo coercitivo de 200 Oe y una magnetización de saturación de $40 \times 10^{-6}$ emu a $300 \mathrm{~K}$.

Palabras clave: Electrodeposión, partículas magnéticas, Microscopía de Fuerza Atómica, Microscopía de Fuerza Magnética.

This work explores the use of one current pulse, which forces the electrode's potential during electrodeposition to adjust to the imposed kinetics for electron transfer. The results obtained on the preparation of nickel particles through a current pulse method to study their magnetic properties in order to develop suitable materials for the magnetic information storage industry are reported. Topographical and magnetic characterization of the electrodeposited particles is presented. Pulse duration effect on the particle size distribution is discussed.

\section{Experimental Setup}

The electrodeposition experiments were carried out in a threeelectrode arrangement. Since the magnetic properties of the deposits were to be characterized, thin films of Indium Tin Oxide (ITO) on glass were selected as working electrodes (WE) to avoid magnetic interactions of the particles with the substrate. Each experiment was strictly performed on fresh ITO electrodes. A Pt wire as counter electrode (CE), and a Ag/ $\mathrm{AgCl}$ electrode (RE) as reference electrode. A $0.05 \mathrm{M} \mathrm{Ni}_{2} \mathrm{SO}_{4}$ with $0.1 \mathrm{M} \mathrm{NaSO}_{4}$ solution was used.

The pulses were applied using an EG\&G Princeton Applied Research potentiostat/galvanostat. Equal intensity pulsed current experiments of $0.5 \mathrm{~mA}$ with different durations, $90 \mathrm{~ms}$, $110 \mathrm{~ms}, 500 \mathrm{~ms}, 1000 \mathrm{~ms}, 5000 \mathrm{~ms}, 10,000 \mathrm{~ms}$ and $15,000 \mathrm{~ms}$, were performed.

Since a current pulse induces a response in which the working electrode polarizes until it reaches a minimum and 
then stabilizes to a fixed value, equivalent values for $E_{1}$ and $\mathrm{E}_{2}$ can be determined from the experimental polarization curves (see Fig. 1) and then be used for a double potential experiment to compare results from both techniques. The lowest value for the potential reached when a pulse of $0.5 \mathrm{~mA}$ of current is applied was $-960 \mathrm{mV}$ and this value was chosen as the nucleation pulse $\left(E_{1}\right)$. The value of stabilization of potential, $-850 \mathrm{mV}$, was chosen as the growth pulse $\left(E_{2}\right)$. Using these parameters, a double potential pulse was set up in order to compare the results obtained with these two different techniques.

After the electrodeposition experiments, samples were topographically characterized using a Veeco Nanoscope IIIa Multimode Atomic Force Microscope with Veeco MESP silicon tips in tapping mode. The images were analyzed using a Matlab routine for image processing [8]. For the magnetic characterization, the same equipment was used in Magnetic Force Microscopy (MFM) mode to obtain the magnetic domain images, and a Superconducting Quantum Interference Device (SQUID) for the magnetization curves.

The MFM images were taken with a lift scan height of $300 \mathrm{~nm}$ and the sample was previously magnetized in longitudinal direction.

\section{Results}

The results obtained by the pulsed current experiments are presented in figure 1 , where the behavior of the potential is shown when a $0.5 \mathrm{~mA}$ pulse is applied to the system. It can be observed that the polarization of the electrode is similar to a two-potential pulse experiment since after the current pulse there is a sharp drop in the electrode potential followed by a recovery to a higher and constant potential. In Figure 1, the time axis is plotted logarithmic scale to allow the inspection of the current curve at the shortest times.

During the first $50 \mathrm{~ms}$ of the current pulse the potential drops to a minimum near $-960 \mathrm{mV}$ which later recovers, reaching a constant value. The first stage will be called a "varying step" and the second stage will be called "stabilization step" of the potential. These stages are related to the nucleation and growth of the particles on the substrate.

Table 1 shows the statistical information of the single current pulse experiments. It is observed that the density of particles increases at very short pulse lengths and then it stabilizes at longer times. The mean particle size does not vary greatly at the early stages of the experiment $(90-110 \mathrm{~ms})$ but then there is a small decrease of size (500-5000 ms) which will be followed by an increase of particle size at longer durations $(10,000-15,000 \mathrm{~ms})$. The standard deviation of the particle size maintains a regular value for the different pulse lengths and it increases on longer time experiments.

Figure 2 shows AFM images where it can be observed the size and distribution of the particles. $15 \mu \mathrm{m} \times 15 \mu \mathrm{m}$ scans were performed to get an overall view of the distribution and a $3 \mu \mathrm{m} \times 3 \mu \mathrm{m}$ scan to observe the particles in more detail.

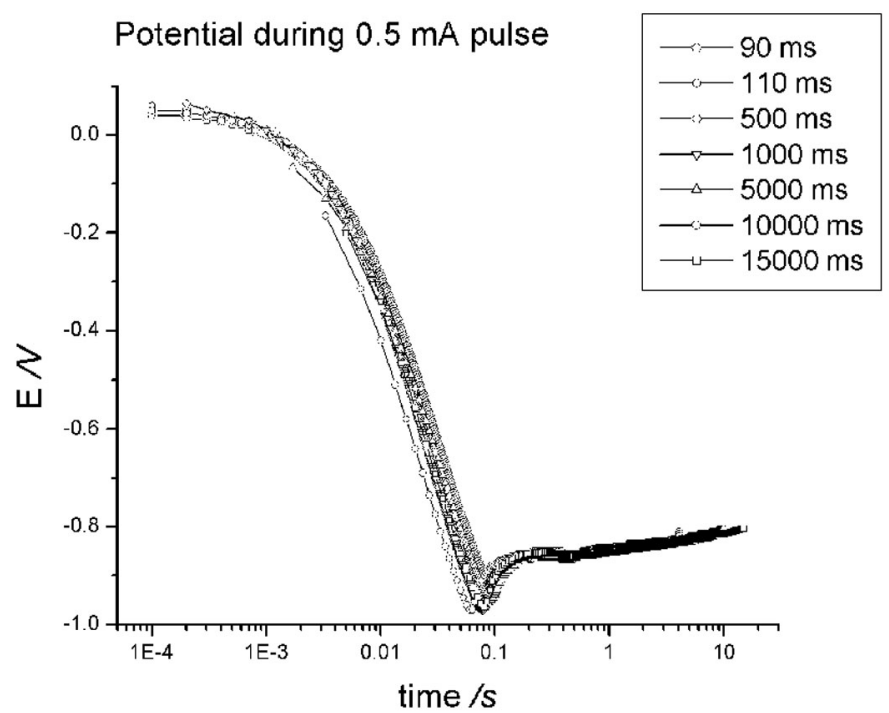

Fig. 1. Potential behavior after a $0.5 \mathrm{~mA}$ pulse is applied to the system. The plot shows several experiments superimposed in which the pulse length is varied from $90 \mathrm{~ms}$ to $15,000 \mathrm{~ms}$.

Table 1. Statistical information of the pulsed current experiments. The data is obtained after the analysis of the AFM images.

\begin{tabular}{cccc}
\hline $\begin{array}{c}\text { Duration of } \\
\text { current pulse }\end{array}$ & $\begin{array}{c}\text { Density of } \\
\text { particles }\end{array}$ & $\begin{array}{c}\text { Mean equivalent } \\
\text { diameter of } \\
\text { particles }\end{array}$ & $\begin{array}{c}\text { Standard Deviation } \\
\text { of equivalent } \\
\text { diameter of particles }\end{array}$ \\
\hline $90 \mathrm{~ms}$ & $0.83 / \mu \mathrm{m}^{2}$ & $162 \mathrm{~nm}$ & $53 \mathrm{~nm}$ \\
$110 \mathrm{~ms}$ & $1.94 / \mu \mathrm{m}^{2}$ & $167 \mathrm{~nm}$ & $43 \mathrm{~nm}$ \\
$500 \mathrm{~ms}$ & $2.01 / \mu \mathrm{m}^{2}$ & $147 \mathrm{~nm}$ & $53 \mathrm{~nm}$ \\
$1000 \mathrm{~ms}$ & $1.85 / \mu \mathrm{m}^{2}$ & $137 \mathrm{~nm}$ & $43 \mathrm{~nm}$ \\
$5000 \mathrm{~ms}$ & $1.05 / \mu \mathrm{m}^{2}$ & $132 \mathrm{~nm}$ & $57 \mathrm{~nm}$ \\
$10,000 \mathrm{~ms}$ & $1.56 / \mu \mathrm{m}^{2}$ & $225 \mathrm{~nm}$ & $64 \mathrm{~nm}$ \\
$15,000 \mathrm{~ms}$ & $1.53 / \mu \mathrm{m}^{2}$ & $246 \mathrm{~nm}$ & $95 \mathrm{~nm}$ \\
\hline
\end{tabular}

In the double potential pulse technique, similar potential values as the ones obtained in the pulsed current experiments were used. The same potential pulse $E_{1}$ to nucleate the particles was used and the duration of the growth pulse $E_{2}$ was varied. Figure 3 shows the current behavior during the potential pulses. It can be observed that during the first pulse it was obtained the typical nucleation curve [4] for electrodeposition and an increase of the current, indicating a possible growth of the particles. The first potential pulse has the same duration as the first current pulse applied, which was $90 \mathrm{~ms}$. In the second potential pulse, the current is nearly stable on $0.5 \mathrm{~mA}$, indicating a growth of the particles at constant speed.

Table 2 presents the statistical information of the double pulsed potential experiments.

The duration of the experiments is very short compared to the duration of the pulsed current experiments. However, 


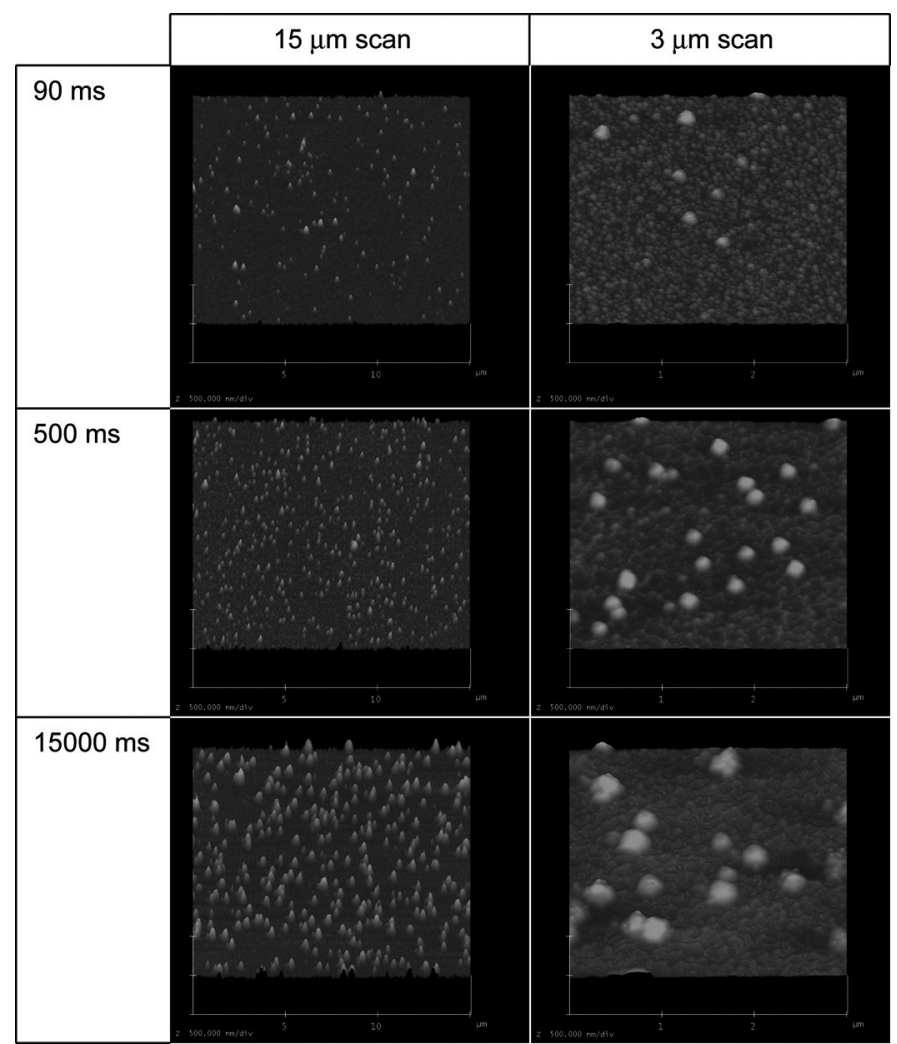

Fig. 2. AFM images show the evolution of the particle deposition growth and the increase in particle density as pulse time increases.

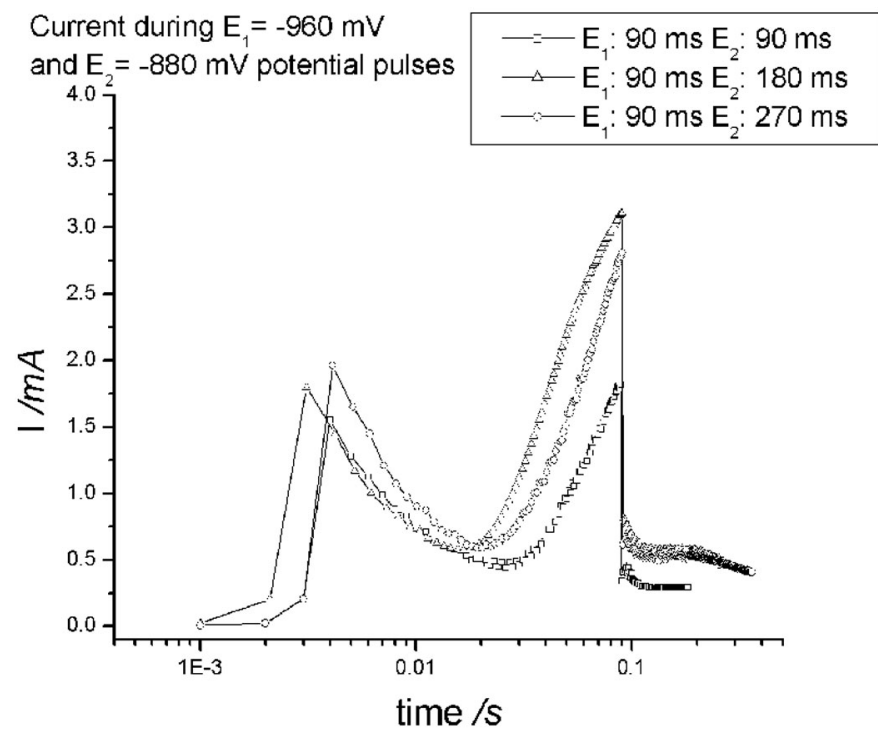

Fig. 3. Current response after applying two potential pulses. The first pulse of $-960 \mathrm{mV}$ for $90 \mathrm{~ms}$ shows the nucleation stage and some growth process, while the second pulse of $-850 \mathrm{mV}$ was applied for 90,180 and $270 \mathrm{~ms}$ to observe the growth mechanism.

the mean particle size and its standard deviation are greater. The density of particles is almost constant. These results are expected by using this technique because the first potential pulse allows the formation of a determined number of nuclei, and the second potential pulse makes them grow.
Table 2. Statistical information of double pulsed potential experiments. The data was obtained after the analysis of the AFM images.

\begin{tabular}{ccccc}
\hline $\begin{array}{c}\text { Duration } \\
\text { of first } \\
\text { potential } \\
\text { pulse }\end{array}$ & $\begin{array}{c}\text { Duration } \\
\text { of second } \\
\text { potential } \\
\text { pulse }\end{array}$ & $\begin{array}{c}\text { Density of } \\
\text { particles }\end{array}$ & $\begin{array}{c}\text { Mean } \\
\text { equivalent } \\
\text { diameter of } \\
\text { particles }\end{array}$ & $\begin{array}{c}\text { Standard Deviation } \\
\text { of equivalent } \\
\text { diameter of } \\
\text { particles }\end{array}$ \\
\hline $90 \mathrm{~ms}$ & $90 \mathrm{~ms}$ & $0.43 / \mu \mathrm{m}^{2}$ & $205 \mathrm{~nm}$ & $82 \mathrm{~nm}$ \\
$90 \mathrm{~ms}$ & $180 \mathrm{~ms}$ & $0.31 / \mu \mathrm{m}^{2}$ & $232 \mathrm{~nm}$ & $77 \mathrm{~nm}$ \\
$90 \mathrm{~ms}$ & $270 \mathrm{~ms}$ & $0.31 / \mu \mathrm{m}^{2}$ & $332 \mathrm{~nm}$ & $117 \mathrm{~nm}$ \\
\hline
\end{tabular}

Figure 4 shows the AFM images obtained in the double pulsed potential experiments. It can be observed that the growth of the particles is very fast at short times compared to the pulsed current experiments. The standard deviation of the particle size also increases with time resulting in a wide particle size distribution.

Particles of ca. $300 \mathrm{~nm}$ were characterized by Magnetic Force Microscopy and their magnetic properties were obtained by SQUID. These particles showed to be ferromagnetic at room temperature $(300 \mathrm{~K})$ with a magnetization of $40 \times 10^{-6}$ emu. Figure 5 shows their magnetization hysteresis and Figure 6 shows the MFM images along with topography.

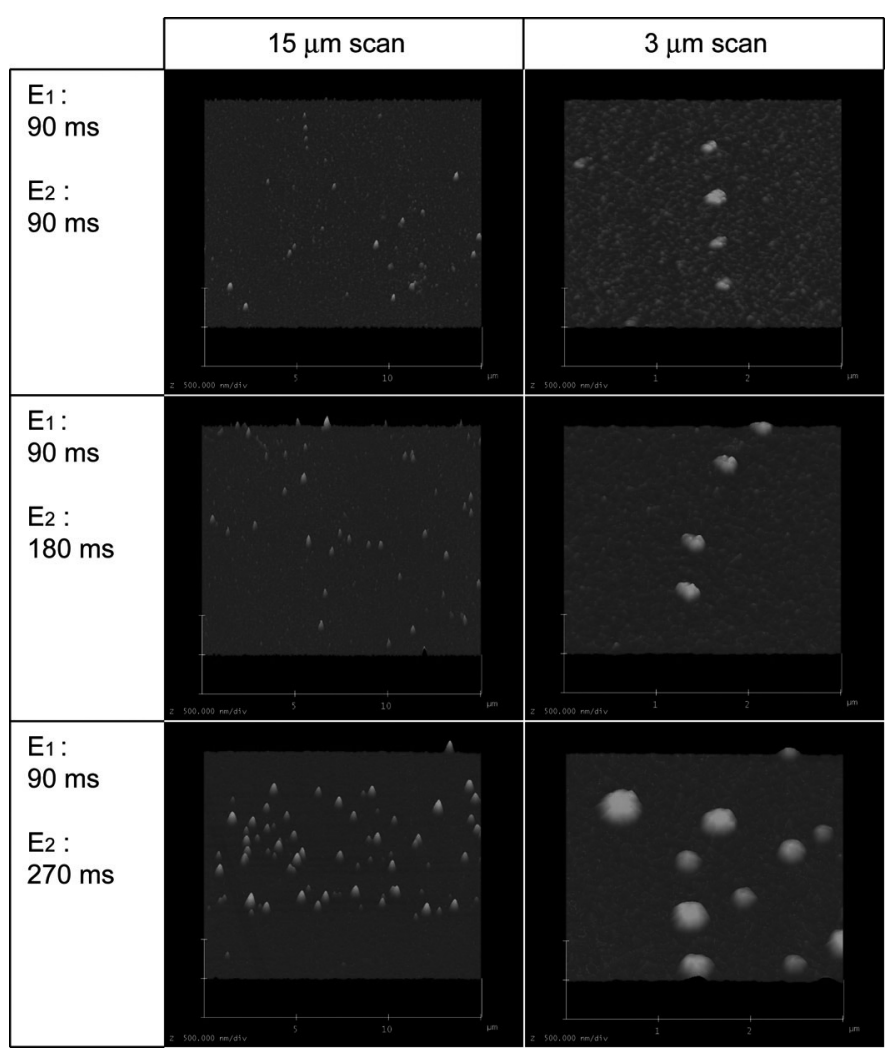

Fig. 4. AFM images show the fast growth of the particles at short times. The density of particles remains very similar at all times. 


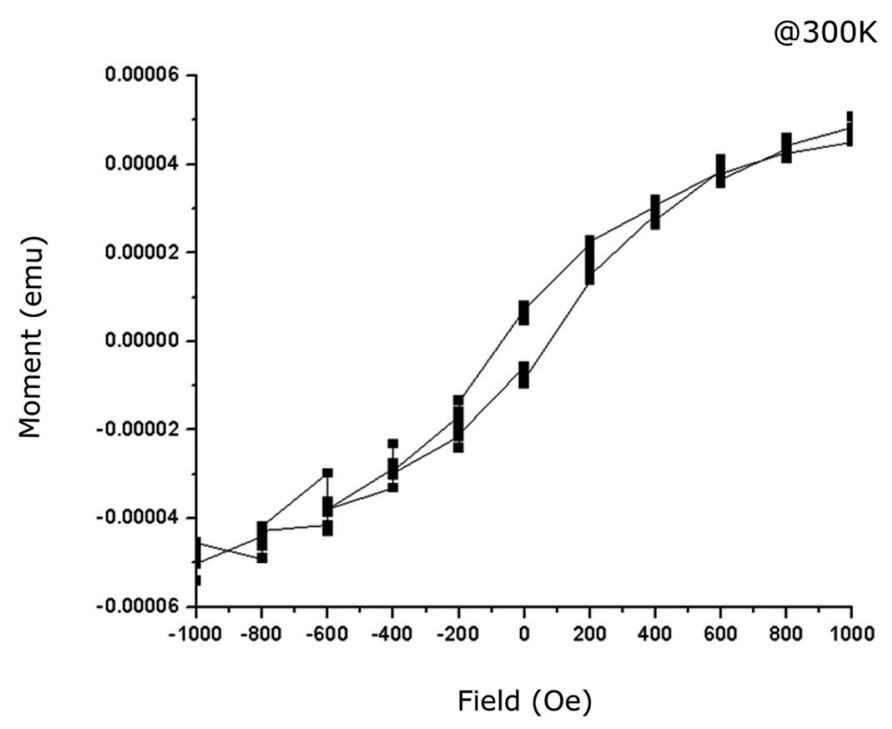

Fig. 5. Magnetization curve of particles $\sim 300 \mathrm{~nm}$ obtained by SQUID. They show ferromagnetic behavior.

\section{Discussion}

It is shown that with the pulsed current method the growth of particles can be achieved more efficiently than that obtained with the double pulse method. The behavior of the cell potential indicates two steps, a 'nucleation process' at the start and a 'growth process' when it stabilizes. The change in the cell potential induced by the current pulse indicates that at short times $(<100 \mathrm{~ms})$ a progressive deposit of particles is achieved. At longer times the growth of the larger particles is limited by diffusion due to a depletion layer [9] established around the particles. Meanwhile, in the regions of the substrate that are free of deposit smaller particles grow. This can be seen in Figure 7, where the particle size distribution plots are shown. The average particle size shifts to larger values keeping the size dispersion almost unchanged. This is interpreted as that the varying part of the pulse promotes nucleation and growth of particles; however, since the system is forced to a deter-

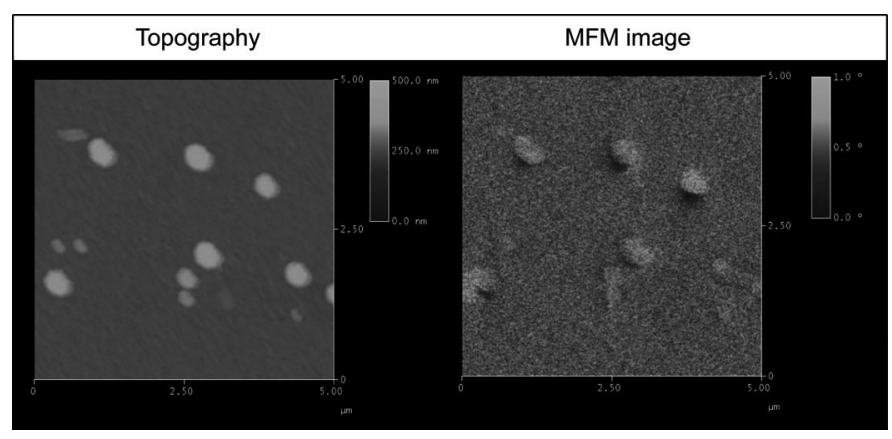

Fig. 6. AFM topography and MFM image of particles $\sim 300 \mathrm{~nm}$. mined speed of electron transfer, the system favors different processes at different sites of the substrate. At the beginning several nuclei are formed and these grow until a certain size is reached which is limited by diffusion, due to the depletion of nickel ions around them. At this point, other nuclei are formed (progressive nucleation), keeping up with the imposed rate of charge transferred. The stabilization will be reached when all nuclei reach the size in which their growth is limited by diffusion. At this stage, the growth of particles is constant to maintain the speed of the process. This results in a low dispersion of particle size.

The double pulse method produces lower density of particles, although the growth of the particles is faster. The nucleation seems to be instantaneous in this case, so, there is not an increase in the number of particles.

The magnetic characterization of the particles show that they are in fact magnetic particles with a well defined hysteresis shown in Figure 5. The particles have a remnant magnetization of $40 \times 10^{-6} \mathrm{emu}$ and a coercive field of 200 Oe which make them soft magnetic material with a small remnant magnetization compared with what is obtained with bulk Nickel. Since SQUID measures a collective magnetization contribution, MFM images were obtained trying to see the behavior of a single particle. The images presented in Figure 6 show that after magnetizing the sample, the magnetic moments of the particles are aligned to give a longitudinal magnetization monodomain image with changes of magnetic signal at the edges and uniform signal above the particles [10].

\section{Conclusion}

An alternative electrodeposition current pulse method is proposed to achieve magnetic Ni particles. The particle size and particle size distribution depend on the duration of the current

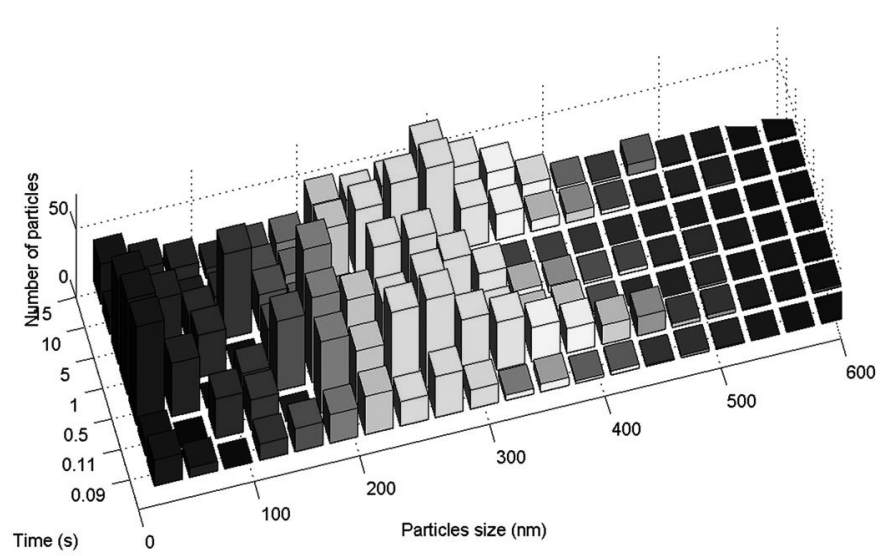

Fig. 7. Image shows the particle distributions of the pulsed current experiments. We observe that at short times, there is an increase on number of particles and at longer times, there is an increase in the size of the particles, leaving the particle size dispersion almost unchanged. 
pulse. An increase on particle density is observed during the varying step of the current pulse and a growth of the particles during the stabilization step of the current pulse. This method allows experiments of longer time periods than the traditional pulsed potential method, which can be taken as an advantage for variable control and sampling accuracy of the equipment.

The SQUID measurements show that the particles of $\sim 300$ $\mathrm{nm}$ were ferromagnetic with a coercive field of 200 Oe and a saturation magnetization of $40 \times 10^{-6} \mathrm{emu}$ at $300 \mathrm{~K}$, while MFM images showed that the particles are single domain.

\section{Acknowledgements}

We thank the CAT-007 and CAT-120 Research Programs by the Tecnológico de Monterrey and CONACyT for the financial support of this research. Special thanks to Alex de Lozanne and Changbae Hyun at the Physics Department of the University of Texas at Austin for their discussions and equipment support in the SQUID measurements.

\section{References}

1. Budevski, E.; Staikov, G.; Lorenz, W. J. Electrochim. Acta. 2000 , 45, 2559-2574.

2. Sandmann, G.; Dietz, H.; Plieth, W. J. Electroanal. Chem. 2000, 491, 78-86.

3. Ueda, M.; Dietz, H.; Anders, A.; Kneppe, H.; Meixner, A.; Plieth, W. Electrochim. Acta 2002, 48, 377-386.

4. Sharifker, B.; Hills, G. Electrochim. Acta 1983, 28, 879-889.

5. Sharifker, B.; Mostany, J. J. Electroanal. Chem. 1984, 177, 13-23.

6. Sluyters-Rehbach, M.; Wijenberg, J. H. O. J.; Bosco, E.; Sluyters, J. H. Electroanal. Chem. 1987, 236, 1-20.

7. Heerman, L.; Tarallo, A. J. Electroanal. Chem. 1999, 470, 70-76.

8. http:/www.nacs.uci.edu/dcslib/matlab/matlab-v60/help/toolbox/ images/gettings.html, accessed August 2006.

9. Penner, R. M. J. Phys. Chem. B 2001, 105, 8672-8678.

10. Rugar, D.; Mamin, H. J.; Guethner, P.; Lambert, S, E.; Stern, J. E.; McFayden, I.; Yogi, T. J. Appl. Phys. 1990, 68, 1169-1183. 